See discussions, stats, and author profiles for this publication at: https://www.researchgate.net/publication/348515972

\title{
Breaking the logic of neoliberal victimhood: Vulnerability, interdependence and memory in Captain Marvel (Anna Boden and Ryan Fleck, 2019)
}

Article in European Journal of Cultural Studies · January 2021

DOI: $10.1177 / 1367549420985839$

CITATIONS

0

1 author:

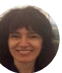

María José Gámez Fuentes

Universitat Jaume I

57 PUBLICATIONS 154 CITATIONS

SEE PROFILE
READS

48

Some of the authors of this publication are also working on these related projects:

Evaluación e indicadores de sensibilidad moral en la comunicación actual de los movimientos sociales. IP: Eloísa Nos Aldás View project

LA RESIGNIFICACION DE LA MUJER-VICTIMA EN LA CULTURA POPULAR: IMPLICACIONES PARA LA INNOVACION REPRESENTACIONAL EN LA CONSTRUCCION DE LA VULNERABILIDAD Y LA RESISTENCIA. Grant number: FEM2015-65834-C2-2-P (MINECO/FEDER). IP: María José Gámez Fuentes View project 


\title{
Breaking the logic of neoliberal victimhood: Vulnerability, interdependence and memory in Captain Marvel (Anna Boden and Ryan Fleck, 2019) ${ }^{1}$
}

\author{
María José Gámez Fuentes \\ Universitat Jaume I (Castellón, Spain)
}

Within the context of thinking about the political work that victimhood does in our public cultures, which this volume invites us to, the aim of this article is to reflect on how popular culture may provide narratives with the potential to fissure the neoliberal logic sustaining the contemporary configuration of female victimhood. In order to do that we will focus, first, on the nuances of the victimhood discourse stemming from the fight against gender violence and its problematical polarization with respect to female empowerment discourses. Secondly, we will turn to the work of Butler $(2004,2005,2009)$ and Butler and Athanasiou (2013) on vulnerability and accountability. We will put it into dialogue with that from Oliver (2001, 2004) and Kaplan (2005) on ethical witnessing to enquire into theoretical and methodological possibilities to approach the analysis and production of cultural products that attempt to break away from that polarization. In order to carry out this research we have operationalized the concept of ethical witnessing into four dimensions of analysis so that we can detect what narrative strategies may constitute ethical witnessing (Gámez Fuentes, Gómez Nicolau and Maseda García, 2016; Gámez Fuentes and Maseda García, 2018; Maseda García and Gómez Nicolau, 2018). The four dimensions are: 1-The relation between the subject victim and those who bear witness; 2 - The very content of the testimony; 3-The approach on vulnerability, resistance and agency; 4-The links between the specific account of violence and the struggle for women's rights and social justice. To exemplify our standpoint we have chosen to apply it to the film Captain Marvel since we believe it articulates the chiaroscuros of trying to dismantle the present matrix of intelligibility on female victimhood in mainstream culture and how, despite that, an approach intertwining different experiences with other vulnerable others (that is, migrant subjects) can be enabled.

\section{Beyond the empowerment and victimization binary}

Long time seems to have passed since the 1979 United Nations (UN) Convention on the Elimination of all Forms of Discrimination against Women (CEDAW), the 1993 Declaration on the Elimination of Violence against Women and the 1995 Beijing Declaration and Platform for Action, all of them initiatives set up to achieve gender equality and eradicate any kind of gender violence. Nowadays, popular culture and social media are plagued with images of women and women initiatives that lead us to think that women can have it all (Banet-Weiser, 2018; Rottenberg, 2018). The 2011 uprisings around the globe 
have revitalized the synergies among different feminisms and celebrity feminism has sprouted reaching audiences never thought of before. Therefore, from TV series to blockbusters along with the celebrated visibility of women in power, it could seem that women finally have achieved equality. In addition, the popular outcry against injustices and violence against women seen through movements such as Me Too, Ni Una Menos or Time's Up has also given ground to believe that the system now no longer turns its back on women but rather offers protection to our vulnerability in the face of violence.

However, it is our contention that empowerment as a response to vulnerability is not only celebrated too soon and too broadly in the public arena, but, also, its focus on the individual disables any form of criticism beyond individual accountability. After all, movements such as Me Too and celebrity feminism have been so successful because they do not focus on structures, but on individual men who have abused and used their privilege and position of power (Banet-Weiser, 2020). Consequently, the restoration of damage has repercussions also in individual terms (by being fired, discredited, publicly shamed, etc.); and it comes from women that represent the idea of success in the liberal matrix: pop stars, actresses, rich and already privileged women that decide to report an oppressive situation, or who broke a patriarchal role, etc. (De Benedictis, Orgad and Rottenberg, 2019).

Furthermore, despite awareness raising efforts, the hegemonic matrix of intelligibility has a long established tradition of defining women as victims before violence by their "injurability", as Butler and Athanasiou (2013) point out. The socially and politically sanctioned script configures women as intrinsically vulnerable, lacking agency and in need of protection, thus justifying the need of the system to assist them. Under this interpretative logic, there is undoubtedly a negative identification of victims as they are defined only by what they have been deprived of (identity, capabilities, will) (Coates and Ridley, 2009). It is not surprising, then, that, as a response to vulnerability, empowerment is being celebrated (Banet-Weiser, 2018; Rottenberg, 2018).

On the other hand, the very same institutions that offer protection and reparative measures do so under the understanding of how a victim should recover (according to the definition of the sovereign subject ruled by the rational action and upon which neoliberalism has capitalized). This is evident when female victims' narratives, actions and decisions are questioned because they fall out of this normative script. As a result, not only women are revictimized by institutions and individuals in an economy of recognition where the subjects of violence are treated as others, but also their subjectivity is ultimately denied. It is in this respect, for instance, that Martinez (2020) analyzes the difficulties that female victims encounter in being recognized as subjects with agency capable of leading independent (that is non-governmental) victims' organization in Spain. Gómez Nicolau (2016) reaches similar conclusions in her study on how Spanish journalists specialized in reporting cases of gender violence divide between the "good" victims (those who followed the predetermined 
institutional path to recovery) from victims that chose more autonomous actions or explored alternative ways. She amplifies this criticism when dealing with the way in which Spanish public policies exclude prostitutes, lesbians and "bad" women as subjects of rights in the fight against gender violence and by doing so simplify its complexity in the social context (Gómez Nicolau, 2018).

Ultimately, women are asked to find their means of empowerment within the structures that regulate to whom and how much power is given. Women's oppression, as well as their "success" is the result of the structure's restricted set of roles and expectations, even in the face of violence and under its supposed protection. Institutions support women's advancement and safety inasmuch as they do not shatter the social and economic conditions that are in the roots of this violence and oppression.

Under this situation, we need to reflect what is at stake when some feminist issues become popular while others are dismissed. Because, the current configuration presents us with two images of women: an empowered female under neoliberal practices or that of a vulnerable victim. While the other side of this coin puts us into a dialectic with the construction of male victimhood and agency. Indeed, the patriarchal reappropiation of the victimhood debate (Banet-Weiser, 2020; Núñez Puente and Gámez Fuentes, 2017) has taken a sinister turn. A misogynist sentiment attached to victimhood has sprouted among men as "aggrieved entitlement" (Kimmel, 2013) and we surprisingly (or not) witness a resurgence of the most machista attitudes, discourses and even political declarations against women. We see it through Donald Trump's discourse in the US, Bolsonaro's in Brazil or the extremeright-wing political party VOX's in Spain. In the words of Banet-Weiser following Chouliaraki (2012): "In this context, victimhood becomes disarticulated from those who suffer and reallocated to the privileged, establishing a symbolic redistribution which appropriates the moral meaning of vulnerability itself" (Banet-Weiser, 2020: 175).

Convinced that counter-narratives breaking away from that neoliberal logic of victimhood are possible, we have been looking during the last years, under the umbrella of Spanish R+D project FEM2015-65834-C2-2-P (MINECO/FEDER; remuvic.eu), into the space between the configuration of women's victimhood devoid of agency and the liberal empowerment that fits solely to already powerful subjects. In order to do that we have searched for and scrutinized narratives that aim at transforming, fighting against, raising awareness or trying to produce a fissure in relation to the hegemonic frame of recognition of gender violence. We contended that it is possible to find, somewhere in between the (post)feminist embodiment of the neoliberal subject and the reified one subsumed under the concept of victim, positions that allow the advancement of a political definition of the subject victim that escapes the neoliberal traps. To reach this goal we have drawn from considerations about vulnerability as a shared feature that can actually foster the mobilization of communities (Butler, 2015; Butler and Athanasiou, 2013; Butler, Gambetti 
and Sabsay, 2016) and we have put it into dialogue with the theoretical concept of "ethical witnessing" (Oliver, 2001; 2004; Kaplan, 2005; Kaplan and Wang, 2004; Wessels, 2010).

The challenge has been to explore what act of naming/representing/giving account may undo the legitimacy of the "scene of address" (Butler, 2005), that is, the established cultural configuration of the actors and agents involved, so that the hegemonic script becomes estranged and the sovereign position of the subject is dislocated? Let us remember in this sense that "[...] naming is not only a site of trauma, but also potentially a strategy of subversive mimesis" (Athanasiou in Butler and Athanasiou, 2013: 139).

It is here that we turn to the concept of "ethical witnessing" (Oliver, 2001, 2004; Kaplan, 2005), since it calls for engaging with the other in a manner that moves beyond the recognition displayed by the hegemonic scene of address. Undoubtedly, recognition is problematic if what is recognized is always something familiar to the subject, because in this context it amounts merely to the assimilation of difference into something familiar. The ethical witnessing paradigm, on the contrary, advocates for a recognition of a difference that goes beyond recognition (Oliver, 2001). After all, recognition is the condition of subjectivity: the subject is a response to an address from the other. Ethical witnessing brings precisely to the center of attention that subjectivity is based on interdependency and, therefore, implies a response-ability, an ability to respond to address; the speaking subject is subject by virtue of address-ability and response-ability. Under these premises witnessing involves "seeing the impossible" so it demands a responsibility on how we respond to the precariousness of the other without subsuming her/him into the established matrix, which continuously interpellates the subject as a vulnerable injured agency-lacking victim or as empowered through neoliberal individualizing practices. However, the cultural discourse that is generated from an ethical witnessing standpoint shall not place itself in the hegemonic (spectacular) space of violence, but instead, generate aspects that destabilize the representational legacy of the heteronormative framework by disclosing the complexities that reveal the interconnected axes of oppression in which violence is generated. The point is not simply to understand and rationalize oppression and violence, but to accept responsibility, allowing for larger social and political meanings (Kaplan, 2004, Kaplan and Wang, 2005; Butler, 2010) that could lead us to imagine shared realities never thought of before.

From this standpoint, "seeing the impossible" becomes then an ethical obligation rooted on interdependency, which, in the realm of cultural production, coincides with Butler's (2020) recent defense of counter-realism in the fight for social justice. The author encourages us to be unrealistic and imagine in a radical way "in order to open up a possibility that others have already closed down with their knowing realism" (Butler interviewed in Gesse, 2020). For "reality" functions in a socio-political manner disavowing accounts that 
may signify "a more radical possibility of equality or freedom or democracy or justice, which means stepping out of a settled understanding" (Butler in Gesse, 2020).

\section{The possibilities of ethical witnessing in Captain Marvel}

Within that framework in mind, we have been looking into popular culture to enquire into what act of naming can enable ethical witnessing and what are the limitations and possibilities opened up by popular narratives. Concretely, our methodology allows us to look into:

1) The relationship generated between the subject-victim who gives account of the violence suffered and those who bear witness of the testimony: the question is to delve into how the narrative instance constructs the spectator's (witness) position and whether and how it reproduces the validating, patronizing, hierarchical and moralizing perspective of the hegemonic discourse. Let us remember that this divides between good and bad victims and, consequently, places the ("good") victim as helplessly bound to tutelage and legitimates her testimony as long as it is coherent with the state and culturally sanctioned configuration.

2) The very content of the testimony: the account given can either recreate the most graphic aspects of (spectacular) violence or, instead, generate novel information that does not accommodate easily within the recognizable pattern of individualized trauma and pain. In this respect, naming the cultural and/or structural constraints that are imbricated in the dominant script of the "truth" of violence, as we know it, adumbrates social demands.

3) The approach on vulnerability, resistance and agency: the objective is to overcome the story of individual "injurability" and the protection of the subject through the system by focusing on non-intelligible autonomous and collective practices of resistance. The story narrated should contemplate vulnerability as mobilizing the agency-building process, not blocking it, and it should allow us to go from the identification of the casuistry of the victim to the realization that victims are subjected by injustices that are intertwined, so, only through interdependence with others, the subject status can be restored. This takes us to the last dimension.

4) The links between specific claims or denounces and the general frame of the struggle for women's rights and social justice: at this point, the question would be to analyze how the narrative enables to connect the present story of violence not only with a matrilineal history of resistance, but also with other past and present fights for social justice (in terms of recognition, redistribution and participation; Fraser and Honneth, 2005). 
The application of this four dimensional model has allowed us in the last few years to explore cultural products, such as TV shows, films and celebrity initiatives, in order to determine the potential to reconfigure the relationship between the subject-victim and the witness, the degree of transgression with respect to reified models of representation, and the connections with women's fights for their rights and other social movements. Now our attention is drawn to the blockbuster Captain Marvel. For, it is our contention that, through applying the theoretical argumentation and methodology developed above, Captain Marvel may help us to explore not only the chiaroscuros and phallacy of the victim versus empowered subject script but also the implicit logic that obscures the divisions that this logic perpetuates.

One would think that a blockbuster Marvel-based such as Captain Marvel, would reproduce the hegemonic economy of recognition where the subjects of violence are either treated as devoid of agency or offered to be empowered through a neoliberal logic. However, the controversy that the film and its female protagonist raised for explicitly adopting standard feminist language to challenge intra and extra diegetic patriarchal injustices (Argyle, 2019), along with the consequent outcry of white angry men (symptomatized in male film critics) and the nerd-culture which chose the angle of victimhood (Leon, 2019), provide a fruitful ground to look into the communicative logic of victimhood.

The film, in line with the feminist zeitgeist, arrives in a moment when other cultural products like Wonder Woman (2017), Jessica Jones (2015-2019), Supergirl (2015-present) and Watchmen (2019) are revitalizing the superhero genre with a feminist slant in order to deal with questions related to the place of women in society ${ }^{2}$. In the respective plots we see how the protagonists have to face the consequences from confronting a hostile environment and use their powers to break away from it and/or defeat it. They seem to be in tune with the current motto that women can do the same as men. However, what singles out Captain Marvel and interests us is the manner in which it problematizes that discourse by intertwining women's vulnerability and gender violence with issues of interdependence and memory.

The film, based on the Marvel Comics character Carol Danvers, was released in USA on March $8^{\text {th }}$, capitalizing from the very beginning on the current feminist celebratory momentum. The story takes place in 1995 in the planet Hala, capital of the Kree Empire. The protagonist is Vers (Brie Larson), a female warrior of the elite Starforce who suffers from amnesia and recurring nightmares where an older woman appears. Her mentor and commander Yon-Rogg (Jude Law), along with the Supreme Intelligence (Annette Bening) that governs the Kree empire, warn her that she has to control her emotions and impulses in order to overcome her rage and the struggle with her past. The Kree are in war with the Skrulls, an alien nation capable to shapeshift and take any form. Vers, along with the rest of the Starforce, is sent into a rescue mission against the Skrulls and ends up being captured. 
During her captivity and posterior escape to Earth, she progressively learns, thanks to the encounter there with S.H.I.E.L.D agent Fury (Samuel L. Jackson) and old friend Maria Rambeau (Lashana Lynch), that the Skrulls are not the terrorists she was told by the Kree but refugees trying to find a home after the Kree destroyed their planet. She also learns that her real name is Carol Danvers, a USA fighter pilot, and the old woman turning up in her nightmares was scientist Dr. Wendy Lawson (also played by Annette Bening), a Kree doubleagent renegade called Mar-Vell, who was in fact helping the Skrulls. The crash plane incident she constantly sees in her dreams refers actually to the day, six years ago, when Lawson and Danvers were test flying a light-speed engine the scientist had been working on for the Skrulls and they were intercepted by Yon-Rogg. After the crash, Mar-Vell asks Danvers to destroy the engine so that it cannot be used by the Kree but in the explosion the latter absorbs its energy (resulting in her acquiring superhuman powers) and gets amnesia. After that, she is taken to planet Hala to recover.

The first thing that calls our attention is how the film intermingles the issue of conforming a personal or collective history/identity related to violence with the politics of emotions and of memory. Most importantly, in that context we need to pay attention to how it scripts the relations/divisions among the different parties concerned in the hegemonic matrix: the subject/s searching for a coherent narrative, the authoritative role of the state (legitimizing or sanctioning) and the "necessary" criminalization of others.

From the beginning, Vers is being told that her frailty resides in her emotions and her past. In the initial training session in which she fights with her commander Yon-Rogg while they talk about her sleep problems, he asks her about the dream. From the conversation, we infer that it is a recurrent dream that upsets her, and he advises her to let go the past because it makes her doubt and this makes her vulnerable. She replies she does not remember her past. This exchange provokes her rage and one of her hands goes in fire. Her superior tells her to control her rage or she will have to commune with the Supreme Intelligence. "There is nothing more dangerous to a warrior than emotion", he adds. When she timidly scoffs at his last comment, he continues "humor is a distraction and anger only serves the enemy". Disregarding the teachings of her mentor, she uses the photon blast of her left hand to strike and defeat him. However, in case she dares to believe that she is in control of her powers or that she owns them, the Supreme Intelligence later reminds her that she was given her special powers to fight for the Kree (the camera offers a close-up of the electronic implant next to her hear lightening as a sign of such power).

Female emotions constructed as problematic by the hegemonic framework seems to echo Kanai $(2015,2017)$ 's critique of postfeminist values. Following Kanai, neoliberal feminism has created a set of "feeling rules" that subjects women to intensified requirements of how to act before insecurity, anger or neediness. According to this, women are expected to respond with resilience, confidence and positive attitude (Favaro and Gill, 2020) so that an approachable femininity continues to be performed; otherwise, they are outside the correct route to empowerment and success. 
Precisely, as if staging those premises, the Intelligence threatens Vers that her powers can be taken away unless she masters them (meaning, she controls her impulses). At the end of the movie it seems that the threat is to be carried out: Yon-Rogg captures Danvers and tells her that thanks to his mentoring he made the best version of herself. Enraged, Danvers tries to activate her photon blasts to fight him but she realizes they lost power. He confirms that her power, as it was given by the Kree, can be taken away. As a response, she finally removes the implant device supposedly enabling her photon blast powers only to realize that it was actually limiting them and without it she actually achieves her full potential.

During the movie, we see through Vers' recollections, that the history of her having been made feel unfit for not following the "correct" path to success or insecure for not owning what she can do, achieve or be, goes long back. And it is not originated on exaggerated emotions but on suffering different forms of violence. People and/or the context had constantly tried to enforce upon her the idea that she is not capable enough to accomplish what she would desire. Through different flashbacks we observe how the system has attempted (and attempts) to abuse, gaslight or victimize her for not living up to expectations in different ways. For example, when Vers ends up being captured by Skrull General Talos, who subjects her to a memory probe, we see Vers as a child driving a kart in a race with another boy, but she goes so fast that she has an accident. An adult male figure tells her that she does not belong there to what she replies that the boy is allowed, though. This 'not belonging' connects her remembrance to another scene where she is hanging from a rope in training military session while she is being told that she is not strong enough by her superior; she falls to the floor and her male trainer reinforces her unsuitability by telling her that they will never let her fly. Another male colleague in a posterior memory scene reiterates that, although she is a decent pilot, she is too emotional and reminds her of the phallic centred male culture that governs her working environment through a reference to the term 'cockpit': "You do know why they call it a cockpit, don't you?"

Cultural violence symptomatized through sexism is reiterated after she escapes to Earth. She is in a parking lot reading a map when a motor biker arrives. He attempts to chat her up and asks her for a smile. Since she pays no attention to him, he calls her a freak. She steals his motorbike in return ${ }^{3}$. Also, sexism is pointed out later in the movie by Rambeau when she has to retort to a patronizing comment by Talos who calls her "young lady". Maria responds: "Call me 'a young lady' again and I'm going to put my foot into places it's not supposed to be".

In any case, we see that, far from impending their actions, women resist in multiple manners the diverse forms of violence they encounter. Danvers is in fact very aware of the threat that assertive and/or powerful women pose to men as she explains to Fury when penetrating areas in the USA facility where they are not allowed. Vers only uses her photon blasts to open doors after Fury's skills cannot facilitate their entrance. Aware that from the beginning they could have entered more easily if Vers had not let him take the initiative, 
Fury asks her why she did not use her powers earlier: "I did not want to steal your thunder", she replies.

Therefore, following the first dimension of our analytical model (the construction of the subject-victim) we can say that the narrative instance constructs a female protagonist/subject that resists the position of victim fabricated for her by the state symbolized in the Kree. Also, despite being a superhero character, she disavows the convenience of adhering to the rational subject position that the Kree hegemonic discourse attempts to enforce upon her as the only option for empowerment. As she herself says at the end of the final battle with her Kree mentor, she has nothing to prove to him; neither to the male authority he symbolizes ${ }^{4}$. Instead, she embraces her supposedly uncontrolled emotions and rage and realizes that her vulnerability does not have to do with them but with a patriarchal culture that has limited her potential. As she points out: "I've been fighting with one hand tied behind my back. What happens when I'm finally set free?"

In that sense, regarding the second dimension of analysis (the account of the violence suffered), her feeling limited by the people and situations she has been placed in contributes to put female victimhood in context and problematize it beyond the sovereign subject matrix of intelligibility. It is important, also, to note here, the role played by characters like Rambeau and Lawson, since they validate Vers' standpoint regarding the cultural and structural violence she has endured.

Indeed, against a patriarchal culture, first, or a Kree system, second, that constantly makes the protagonist feel unfit or awkward unless she complies with its expectations, we also witness how the narrative makes clear that female relations and support are essential to whom she is and what she has achieved. For example, the cockpit scene is followed by another memory recollection in which she is with her friend Rambeau in a bar having fun together and afterwards by another one in which she is looking at the stars with her friend's daughter Monica (Akira Akbar) while they are waiting to be called for dinner by the little girl's mother. Also, Dr. Wendy Lawson and her share in a conversation the satisfaction they feel for their job as pilots. Through these instances, Vers' identity and possibilities of resistance are associated to female alliances and matrilineage.

To reinforce that the collective force stemming from female sisterhood and matrilineal legacy is the key to resist patriarchal violence, beyond race and sexual orientation differences, the movie displays several strategies: it casts women from different races (Rambeau being played by Jamaican descent actress Lashana Lynch), the plot hints at a possible romantic relationship between Danvers and her friend, and in several scenes the importance of synchronical and diachronical female interdependence is emphasized. For instance, when the protagonist finally finds Rambeau, the latter tells her that they were working with Lawson testing her engine because women were not allowed to fly combat and that was their only chance to do something that mattered. Maria also later reminds Danvers that she, not only was her best friend, but the one who supported her as a mother and a pilot. "You were the most powerful person I knew way before you could shoot fire from your fists", Maria adds. They fuse in an embrace as Maria says: "I got you". Moreover, 
matrilineage is underlined when in checking photos from her shared past life with Maria and her daughter Monica, the protagonist and the girl appear in fancy costumes emulating Amelia Earhart and Janice Joplin. In a posterior scene, Maria's daughter has to convince her mother to accompany Danvers as copilot with the argument that, otherwise, she would not be setting a good example for her daughter.

Thus, before a Kree system that attempts to erase the importance of sisterhood and matrilineal legacy and pretends to be the sole source of the protagonist's identity and power, the narrative plays with the trope of amnesia to put forward, what Plain and Sellers (2007) define as the tension between "the power of feminism and its increasing spectrality" (cited in Munford and Waters, 2014: 30). For, contemporary feminism seems strangely ambivalent in recognizing and/or recuperating the legacy of previous women's struggles. In this sense, Captain Marvel constitutes a strong bet against the idea that "the postfeminist text is often marked by amnesia" (Munford and Waters, 2014: 30). Instead, the film, places the question of memory and the fabricated and selective nature of it in relation to what is made visible and by whom, regarding women's empowerment, as essential in the configuration of a personal and collective history.

So, with regards to the third dimension of analysis, we can observe that vulnerability, resistance and agency are not approached from a neoliberal individualistic position, instead, interdependency is emphasized. The protagonist's possibilities of "success" are linked to sorority, reclaiming personal and historical memories (beyond authoritative accounts) and the recuperation of a matrilineal legacy of fight. However, the film might be warning us also against automatically reading women in power as enabling other women for what they are/desire to be. We refer to the fact that both the Supreme Intelligence and Dr. Lawson are played by the same actress. So although Dr. Lawson is part of a matrilineal empowering system, the same cannot be said of the Supreme Intelligence ${ }^{5}$.

This, in turn, takes us to the last analytical dimension: the links between the concrete story of violence and the general frame of the struggle for women's rights and other social justice struggles. It is interesting to note in this respect that Captain Marvel depicts vulnerability as a shared condition across not only gender boundaries but also geographical ones thanks to the recourse of the Skrulls as refugees. The question of interdependency being linked to vulnerability before patriarchy, memory and the politics of emotions undergoes, therefore, a turn of the screw in the manner that the film constructs Vers' story in relation to that of the Skrulls.

Indeed, the relation between the protagonist and the initially constructed as antagonist others, defined as terrorists by the Kree, is first tackled when Vers' status as a victim is named as such by the Supreme Intelligence. In the first encounter between the latter and Vers, the Supreme Intelligence underlines that the struggles with her emotions and with her past are due to her being a victim of the Skrulls; her nightmares and amnesia being a consequence of something to do with the horrors of the Skrull expansion: they are impostors who infiltrate into the Kree nation and take over their planet. However, as the story line develops it is proven that Vers' victimhood, although linked to the Skrulls', is not 
in the manner fabricated by the Kree, but rather in their common attempt to find a home, may that be a destiny (in the case of the Skrulls' migrant situation) or origins (in the case of Vers' amnesia).

Thus, in the Trump era of fabricated news, the narrative seems to be equating a woman's ordeal to break away from a distorted personal history (of who she is and where her powers reside) to that of refugees. In that sense, the movie sustains the possibility of reading Vers's vulnerability as a woman and the Skrulls' vulnerability as refugees as shared vulnerability (Butler, 2015, 2020; Butler and Athanasiou, 2013; Butler, Gambetti and Sabsay, 2016) against the logics of a totalizing empire narrative. In both cases, Captain Marvel asserts the legitimacy of reclaiming both a personal narrative and a collective one when confronting a hegemonic discourse (government or political climate) that, on the one hand, gaslights and/or advocates for female empowerment based only on rational and invidualistic parameters or, on the other, criminalizes migrant groups crossing borders. Moreover, the film displays that confrontation and resistance are only possible if acknowledging interdependency with whom sustains us throughout the trauma and pain that systemic abuse, discrimination and violence can cause. Vers and the Skrulls sharing forces to fight the Kree illustrates also Butler's words: "People in the world have every reason to be in a state of total rage. What we do with that rage together is important" (Butler in Gesse, 2020).

To conclude, after having explored the narrative possibilities that Captain Marvel offers, it can be said that, despite being a blockbuster, it opens new creative ventures to stage and examine the current polarization logics of postfeminist female empowerment and victimhood from an ethical witnessing perspective. For, the film goes beyond the dominant script of the "truth" of violence by displaying the structural and cultural constraints that women share against the sanctioned tale of individual memory, vulnerability and trauma before violence. Also, it traces a continuum among the precariousness of diverse vulnerable subjects.

In sum, we believe that within the present debate on the logics of victimhood and the place of popular culture in it, powerless groups can definitely benefit from a cultural discourse which encourages us to suspend our belief and imagine other (unrealistic) worlds that, on the one hand, disavow exclusionary imaginations of 'us' and 'them' and, on the other, disregard "authorized" neoliberal accounts of who we are, how are we supposed to feel, how can we be empowered and who the enemy is. Captain Marvel opens the door to explore cultural strategies in the liminal space of enunciation between empowerment and victimhood by bringing into the debate the need to look at the politics of emotions, interdependency and memory in order to strange the prevailing configuration of vulnerability sustaining the dominant configuration of the victim. 


\section{REFERENCES}

Argyle S (2019) The nerds who hate 'Captain Marvel'. The Outline, 6 March. Available at: https://theoutline.com/post/7143/captain-marvel-brie-larson-comicsgateyoutube?zd=1andzi=usxrfzca Banet-Weiser S (2018) Empowered: Popular Feminism and Popular Misogyny. Durham, NC: Duke University Press.

- (2020) Radical vulnerability: feminism, victimhood and agency. In: Gámez Fuentes MJ, Núñez Puente S and Gómez Nicolau E (eds.) Re-writing Women as Victims: From Theory to Practice. London: Routledge, pp. 167-180.

Butler J (2004) Precarious Life: The Powers of Mourning and Violence. London: Verso.

- (2005) Giving an Account of Oneself. New York: Fordham University Press.

- (2009) Frames of war: When is Life Grievable? London: Verso.

- (2010) Performative Agency. Journal of Cultural Economy, 3(2): 147-161

- (2015) Notes toward a Performative Theory of Assembly. Cambridge, Massachusetts: Harvard University Press.

- (2020) The Force of Nonviolence. London: Verso.

Butler J and Athanasiou A (2013) Dispossession: the Performative in the Political: Conversations with Athena Athanasiou. Cambridge, UK: Polity Press.

Butler J, Gambetti Z and Sabsay L (eds.) (2016) Vulnerability in Resistance. Durham, NC: Duke University Press

Chourialaki L (2012) The Ironic Spectator: Solidarity in the Age of Post-Humanitarism. Cambridge, UK: Polity Press.

Coates L and Ridley P (2009) Representing victims of sexualized assault. In: Faulkner, Ellen and MacDonald, Gayle (eds.) Victim no More; Women's resistance to Law, Culture and Power. Halifax: Fernwood Publishing Co., pp. 109-124.

De Benedictis S, Orgad S and Rottenberg C (2019) \#MeToo, popular feminism and the news: A content analysis of UK newspaper coverage. European Journal of Cultural Studies, 22(5-6): 718-738

Favaro L and Gill R (2020) 'Pump up the positivity': neoliberalism, affective entrepreneurship and the victimhood/agency debate. In: Gámez Fuentes MJ, Núñez Puente S and Gómez Nicolau E (eds.) Re-writing Women as Victims: From Theory to Practice. London: Routledge, pp. 153-166.

Fraser N and Honneth A (2005) Redistribution or Recognition? A Political- Philosophical Exchange. London: Verso.

Gámez Fuentes MJ and Maseda García R (eds.) (2018) Gender and Violence in Spanish Culture: From Vulnerability to Accountability. New York: Peter Lang.

Gámez Fuentes MJ, Gómez Nicolau E and Maseda García R (2016) Celebrities, gender violence and women's rights: towards the transformation of the framework of recognition? Revista Latina de Comunicación Social, 71: 833-852. 
Gesse M (2020) Judith Butler wants us to reshape our rage. The New Yorker, 9 February. Available at: https://www.newyorker.com/culture/the-new-yorker-interview/judith-butlerwants-us-to-reshape-our-rage

Gideonse ThK (2019) Captain Marvel smirks all the way to the bank. Anthropology News, 16 April. Available at: https://anthrosource.onlinelibrary.wiley.com/doi/epdf/10.1111/AN.1149

Gómez Nicolau E (2016) Culpabilización de las víctimas y reconocimiento: límites del discurso mediático sobre la violencia de género. Feminismo/s, 27: 197-218.

- (2018) Silenced voices: prostitutes, lesbians and "bad" women in Spanish public policies on gender violence. In: Gámez Fuentes MJ and Maseda García R (eds.) Gender and Violence in Spanish Culture. From Vulnerability to Accountability. New York: Peter Lang, pp. 57-74. Kaplan A (2005) Trauma Culture. The Politics of Terror and Loss in Media and Literature. New Brunswick, New Jersey, and London: Rutgers UP.

Kaplan A and Wang B (eds) (2004) Trauma and Cinema. Cross-Cultural Explorations. Hong Kong: Hong Kong University Press.

Kanai A (2015) WhatShouldWeCallMe? Self-branding, individuality and belonging in youthful femininities on Tumblr. M/C Journal, 18(1).

- (2017) The best friend, the boyfriend, other girls, hot guys, and creeps: The relational production of self on Tumblr. Feminist Media Studies, 17(6): 911-925.

Kimmel M (2013) Angry White Men: American Masculinity at the End of an Era. New York: Nation Books.

Leon M (2019) How Brie Larson's 'Captain Marvel' made angry white men lose their damn minds. The Daily Beast, 6 March. Available at: https://www.thedailybeast.com/how-brielarsons-captain-marvel-made-angry-white-men-lose-their-damn-minds

Martínez M (2020) Collective action and organisation against gender violence in Spain. In: Gámez Fuentes MJ, Núñez Puente S and Gómez Nicolau E (eds.) Re-writing Women as Victims: From Theory to Practice. London: Routledge, pp. 98-111.

Maseda García R and Gómez Nicolau E (2018) Time's Up, celebrities and the transformation of gender violence paradigms: The case of Oprah Winfrey's Speech at the Golden Globes. Teknokultura, 15 (2): 193-205.

Munford R and Waters M (2014) Feminism and Popular Culture. Investigating the Postfeminist Mystique. New Brunswick, New Jersey: Rutgers University Press.

Núñez Puente S and Gámez Fuentes MJ (2017) Spanish feminism, popular misogyny and the place of the victim. Feminist Media Studies, 5(17): 902-906.

Oliver K (2001) Witnessing: Beyond Recognition. Minneapolis: University of Minnesota Press.

- (2004) Witnessing and testimony. Parallax, 10(1): 79-88 
Plain G and Sellers S (2007) Introduction. In: Plain, Gill and Sellers, Susan (eds.), A Cambridge History of Feminist Literary Criticism. Cambridge: Cambridge University Press, pp. 1-3 Rottenberg, C (2018) The Rise of Neoliberal Feminism. Oxford: Oxford University Press. Spiers E (2018) Hollywood's feminized movie reboots are not particularly feminist. Quartz, 15 October. Available at: https://qz.com/quartzy/1424403/oceans-8-captain-marvel-and-theproblem-with-female-movie-reboots/

Wessels E (2010) The Politics of Ethical Witnessing: The Participatory Networks of 9/11 Media Culture. Thesis submitted to the University of Minnesota.

\footnotetext{
${ }^{1}$ This work was supported by the Spanish Ministry of Economy and Competitivity (MINECO-FEDER) under Grant FEM2015-65834-C2-2-P and by the Research Programme of Universitat Jaume I (Castellón, Spain) under Grant UJI-B2019-13.

2 The same can be said with respect to the increasing all-female reboots of classic all-male films like Ghostbusters (2016) or Ocean's 8 (2018) (Spiers, 2018), or movies which include female super heroes like in Black Panther (2018), Avengers: Infinity War (2018) and Avengers: Endgame (2019).

3 This has been interpreted as a trolling response to the internet criticisms from aggrieved men who complained about the fact that from the trailer the character interpreted by Brie Larson did not smile (Gideonse, 2019).

${ }^{4}$ We thank the reviewers for drawing our attention to this aspect.

${ }^{5}$ We thank the reviewers for drawing our attention to this aspect.
} 